Letter to the Editor

\title{
Severe CMV Infection after Chemo-Immunotherapy with Dose- Reduced Bendamustine and Rituximab in a Mantle Cell Lymphoma Old Patient
}

Keywords: Mantle cell lymphoma; Bendamustine; CD4+ lymphopenia; Non-Hodgkin-s lymphoma; Cytomegalovirus.

Citation: Magliano G., Cuccaro A., D’Alò F., Maiolo E., Bellesi S., Hohaus S., Bacigalupo A., Pagano L. Severe CMV infection after chemoimmunotherapy with dose- reduced Bendamustine and Rituximab in a mantle cell lymphoma old patient. Mediterr J Hematol Infect Dis 2021, 13(1): e2021054, DOI: http://dx.doi.org/10.4084/MJHID.2021.054

This is an Open Access article distributed under the terms of the Creative Commons Attribution License (https://creativecommons.org/licenses/by-nc/4.0), which permits unrestricted use, distribution, and reproduction in any medium, provided the original work is properly cited.

\section{To the editor.}

We discuss the case of a 74-year old male patient with mantle cell lymphoma, who faced severe cytomegalovirus (CMV) infection after the fifth cycle of first-line chemo-immunotherapy with a dose-reduced bendamustine and rituximab regimen.

The patient came to our attention in May 2017. He reported weight loss of $10 \%$ and night sweats in the previous two months; his performance was reduced (ECOG 3). His past medical history was unremarkable.

Bone marrow biopsy revealed a pleomorphic variant of mantle cell lymphoma. The stage was IVB (superior and inferior nodal site involvement, B symptoms). MIPI score was 9.4 (high risk): age 74 years, LDH $3116 \mathrm{UI} / \mathrm{L}$, WBCs 3.01 x10^9/L, ECOG 3, Ki67 85\% on histology.

At diagnosis, CD4 count was $0.24 \times 10^{\wedge} 9 / \mathrm{L}(0.63$ 1.4), with inversion of $\mathrm{CD} 4 / \mathrm{CD} 8$ ratio. There were no other detectable causes of immune suppression.

Considering age and performance status, we started chemo-immunotherapy with rituximab $\left(375 \mathrm{mg} / \mathrm{m}^{2}\right.$ on day 2)-bendamustine (70 mg/m $\mathrm{m}^{2}$ on day 1-2) every 28 days. As a common clinical practice, we did not perform antiviral prophylaxis.

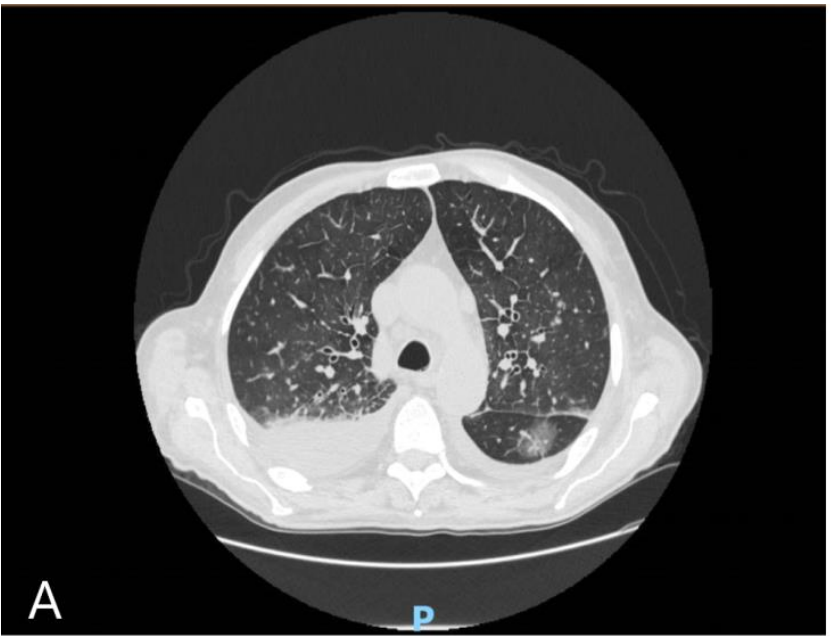

Two weeks after the fifth cycle, the patient was admitted to our hospital with fever $\left(38.5^{\circ} \mathrm{C}\right)$, dyspnea, and diarrhea. Chest X-ray revealed interstitial pneumonitis with bilateral basal thickening and left pleural effusion. Thoracic CT scan showed pulmonary edema with diffuse ground-glass opacities, bilateral pleural effusions, and small pericardial effusion of $8 \mathrm{~mm}$ (Figure 1).

Hemoglobin levels were $8.1 \mathrm{~g} / \mathrm{dL}$, WBCs were $2.37 \times 10^{\wedge} 9 / \mathrm{L}$, plts were $55 \times 10^{\wedge} 9 / \mathrm{L}$. Intravenous antibiotic therapy with piperacillin-tazobactam and levofloxacin and oxygen support was started. Unfortunately, fever persisted with no clinical improvement (Table 1).

On the sixth day of hospitalization blood PCR test for CMV yielded 1,400,000 copies $/ \mathrm{mL}$, and intravenous antiviral therapy with ganciclovir $5 \mathrm{mg} / \mathrm{Kg}$ bid was started (Figure 2).

After one day of antiviral therapy, the patient developed neurological symptoms with paresthesia and tremor. For the suspect of an adverse drug effect to ganciclovir, antiviral treatment was modified to

Figure 1. Thoracic CT scan with contrast enhancement at admission (A) and on day 25 of hospitalization (B).

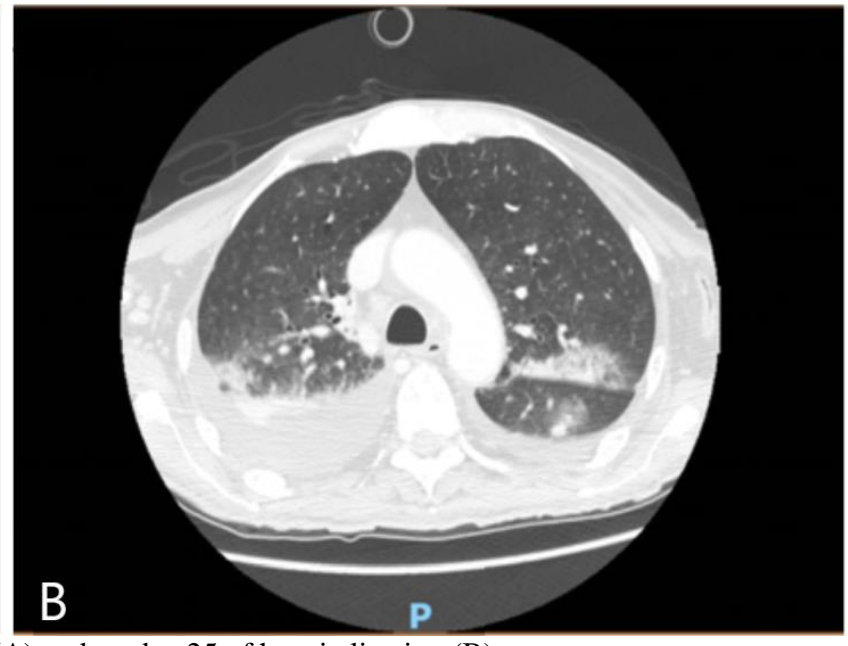


Table 1. Laboratory parameters during hospitalization.

\begin{tabular}{|c|c|c|c|}
\hline \multicolumn{2}{|c|}{ Laboratory parameters on admission } & At the time of death & Normal range \\
\hline $\begin{array}{l}\text { Haemoglobin } \\
\text { Platelet count } \\
\text { WBC }\end{array}$ & $\begin{array}{r}8.1 \mathrm{~g} / \mathrm{dl} \\
55 \times 10^{\wedge} 9 / 1 \\
2.37 \times 10^{\wedge} 9 / 1\end{array}$ & $\begin{array}{l}9.5 \mathrm{~g} / \mathrm{dL} \\
92 \times 10^{\wedge} 9 / \mathrm{L} \\
2.46 \times 10^{\wedge} 9 / \mathrm{L}\end{array}$ & $\begin{array}{r}12-14 \mathrm{~g} / \mathrm{dl} \\
150-450 \times 10^{\wedge} 9 / 1 \\
4.0-10 \times 10^{\wedge} 9 / \mathrm{L}\end{array}$ \\
\hline \multicolumn{4}{|l|}{ Chemistry } \\
\hline $\begin{array}{l}\text { LDH } \\
\text { GPT } \\
\text { Creatinine } \\
\text { Total bilirubin } \\
\text { Albumin } \\
\text { Total proteins } \\
\text { PCR }\end{array}$ & $\begin{array}{r}263 \mathrm{UI} / 1 \\
19 \mathrm{UI} / 1 \\
0.96 \mathrm{mg} / \mathrm{dl} \\
0.6 \mathrm{mg} / \mathrm{dL} \\
2.8 \mathrm{~g} / 1 \\
5.1 \mathrm{~g} / \mathrm{l} \\
55.3 \mathrm{mg} / \mathrm{L}\end{array}$ & $\begin{array}{l}301 \mathrm{UI} / \mathrm{L} \\
11 \mathrm{UI} / \mathrm{L} \\
0.61 \mathrm{mg} / \mathrm{dL} \\
1.0 \mathrm{mg} / \mathrm{dL} \\
2.7 \mathrm{~g} / \mathrm{L} \\
5.0 \mathrm{~g} / \mathrm{L} \\
51.6 \mathrm{mg} / \mathrm{L}\end{array}$ & $\begin{array}{r}230-460 \mathrm{UI} / \mathrm{l} \\
7-45 \mathrm{UI} / \mathrm{l} \\
0,7-1,2 \mathrm{mg} / \mathrm{dl} \\
0.3-1.2 \mathrm{mg} / \mathrm{dl} \\
34-48 \mathrm{~g} / \mathrm{L} \\
65-85 \mathrm{~g} / \mathrm{L} \\
5 \mathrm{mg} / \mathrm{L}\end{array}$ \\
\hline \multicolumn{4}{|c|}{ Coagulation tests } \\
\hline $\begin{array}{l}\text { aPTT } \\
\text { Fibrinogen } \\
\text { INR } \\
\text { D-Dimer }\end{array}$ & $\begin{array}{r}36.9 \mathrm{sec} \\
306 \mathrm{mg} / \mathrm{dl} \\
1.05 \\
6995 \mathrm{ng} / \mathrm{ml} \\
\end{array}$ & $\begin{array}{l}38.8 \mathrm{sec} \\
611 \mathrm{mg} / \mathrm{dL} \\
1.09 \\
2345 \mathrm{ng} / \mathrm{mL}\end{array}$ & $\begin{array}{r}20-38 \mathrm{sec} \\
200-400 \mathrm{mg} / \mathrm{dL} \\
0,8-1,2 \\
<500 \mathrm{ng} / \mathrm{mL} \\
\end{array}$ \\
\hline
\end{tabular}

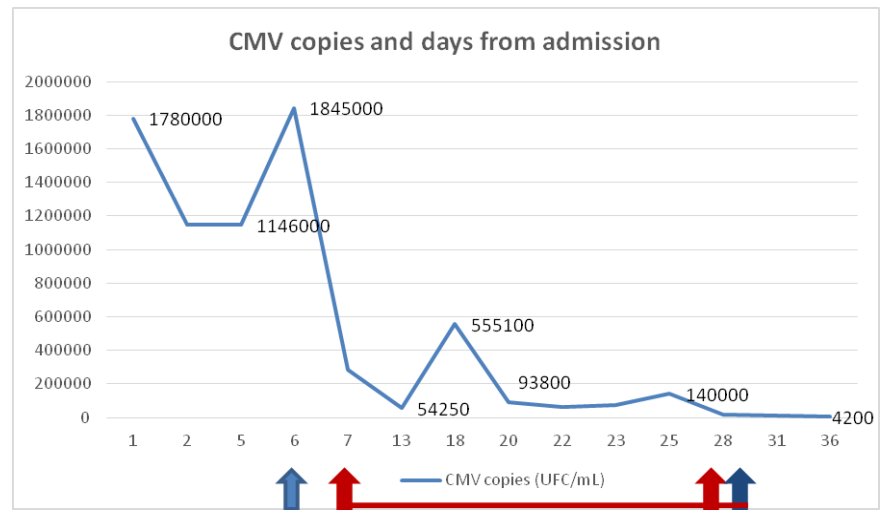

Figure 2. CMV copies and days from admission. Blue arrow shows intravenous antiviral therapy with ganciclovir, while the red arrow stands for foscarnet.

foscarnet $20 \mathrm{mg} / \mathrm{Kg}$.

Despite antiviral therapy, clinical conditions kept worsening, as the patient required increased oxygen support and remained febrile. CT scan of the thorax performed on day 25 revealed new ground-glass opacities in the superior pulmonary lobes. In addition, pericardial effusion increased to $13 \mathrm{~mm}$ (Figure 1).

Microbiological examination of bronchoalveolar lavage yielded 54,250 copies of CMV-DNA $/ \mathrm{ml}$ bronchoalveolar fluid, $462 \mathrm{pg} / \mathrm{ml}$ of Candida antigen, and $0.7 \mathrm{pg} / \mathrm{mL}$ Aspergillus spp. In addition, intravenous antifungal therapy with voriconazole was added.

CMV copy number in peripheral blood remained high $(140,000 / \mathrm{mmc})$, and antiviral therapy was changed to ganciclovir on day 29 of hospital admission. Lymphocyte counts decreased: CD4+ cells, $0.042 \mathrm{x}$ $10^{\wedge} 9 / \mathrm{L}(0.63-1.40), \mathrm{CD} 8,0.12 \times 10^{\wedge} 9 / \mathrm{L}(0.35-0.81)$, CD56+, $0.093 \times 10^{\wedge} 9 / \mathrm{L}(0.14-0.42)$, and CD19 cells were undetectable. After another six days, the patient developed psychomotor agitation. Antiviral therapy was stopped. The patient died after two other days of hospitalization.
Discussion. Mantle cell lymphoma (MCL) primarily occurs among elderly patients with a median age greater than 60 years. ${ }^{1}$ Half of these patients are not eligible for standard therapy that includes autologous blood stem cell transplantation due to the presence of comorbidities and to the general performance status.

Bendamustine-rituximab (BR) is currently becoming the treatment of choice in older patients with indolent non-Hodgkin lymphomas (NHL) and MCL, ${ }^{2,3}$ having a favorable toxicity profile. ${ }^{2}$

However, the BR combination has been shown to cause myelosuppression, including combined $\mathrm{T}$ and $\mathrm{B}$ cell lymphopenia, with more profound $\mathrm{T}$ cell depletion. ${ }^{4}$ In addition, Saito and colleagues observed that the median lymphocyte and CD4+ T-cell count decreased significantly after the first administration of bendamustine in patients with relapsed or refractory indolent B-NHL. ${ }^{5}$

Infection rates in patients receiving bendamustine in randomized, controlled clinical trials range from $6 \%$ to $55 \%$, with $1 \%$ to $35 \%$ of them being grade 3 to $4 .{ }^{4} \mathrm{CD} 4+$ recovery after BR is often delayed and consequently correlated with the risk of any type of infection. Time to recovery to pre-treatment values ranges from 7-9 months $^{5}$ to more than two years after the last administration. In addition, low end-of-treatment absolute lymphocyte count (ALC) and a total dose of bendamustine higher than $1080 \mathrm{mg} / \mathrm{m}^{2}$ have been reported to predict delayed CD4+ recovery. ${ }^{6}$

Receiving bendamustine as part of later lines of therapy (third-line and above treatment) has been identified as another risk factor for infections. ${ }^{7,8}$

This impairment in $\mathrm{T}$ cell immunity has been shown to trigger, in particular, CMV reactivation. For example, in the study by Saito, CMV antigenemia was detected in 15 of 56 patients $(27 \%)$ and CMV colitis in 1 patient. All these events occurred within nine months after completion of treatment. ${ }^{5,8,9}$ 
In a recent real-world study on 167 NHL, age $\geq 60$ was a risk factor for CMV reactivation in patients treated with first-line bendamustine. ${ }^{10}$

Another report by Cona and colleagues described a severe, disseminated form of CMV reactivation in a 75year-old lymphoplasmacytic lymphoma patient, who faced a profound imbalance in phenotype and function of B-and T-cell subsets after BR. ${ }^{11}$

Our case highlights how severe CMV reactivation can occur in the elderly MCL patient treated with bendamustine, even when administered at a lower dose (our patient had received a total of $700 \mathrm{mg}$ ) and as part of first-line therapy.

Our patient presented with low CD4+ cell counts $\left(0.24 \times 10^{\wedge} 9 / \mathrm{L}\right)$ at diagnosis, before starting treatment, without having other detectable causes of immune suppression (e.g., co-infections).

Age-related changes in the immune system, collectively called immunosenescence, in addition to immune suppression correlated with the underlying disease, might have contributed to CMV reactivation after BR.

Despite treatment with ganciclovir and foscarnet, CMV pneumonitis did not resolve, and immune suppression was persistent, as CD4+ cells were $0.042 \times 10^{\wedge} 9 / \mathrm{L}$ on day 22 .

We could not assess if CMV pneumonia was the single main cause of death, as an autopsy could not be performed. However, considering the significant worsening of the clinical conditions (together with the radiological picture), we believe it contributed to the dismal outcome.

Lymphocyte profiling and monitoring ALC and CD4+ count before, during, and after the end of treatment could help to identify patients who might be at particular risk of delayed $\mathrm{CD} 4+$ recovery and consequently of viral and opportunistic infectious complications. ${ }^{6}$

A low CD4+ count could be a trigger to monitor also CMV DNA. However, studies are needed to assess the effectiveness of a pre-emptive antiviral therapy in this context, as recommended in 2017 by the UK Medicines and Healthcare products Regulatory Agency (MHRA). ${ }^{12}$

A recent study by Fung and colleagues estimated that antiviral prophylaxis could prevent one CMV case every 269 bendamustine-treated patients with NHL. ${ }^{7}$

In our case, bronchoalveolar lavage detected a concomitant fungal infection, although CT of the thorax was suggestive for CMV pneumonia. Neutropenia was an additional risk factor for fungal infection.

In an Israeli retrospective analysis, the frequency of fungal infections in 183 patients affected by lymphoproliferative neoplasms and treated with a bendamustine-containing regimen was $3.8 \% .^{13}$

In the study by Fung, bendamustine treatment was associated with a higher incidence of neutropenia and candida infection. $^{?}$

Conclusions. Our case is an alert for clinicians that BR can be associated with severe infections in elderly patients even in first-line therapy at a reduced dose. However, as BR is otherwise well tolerated, the infectious risk should not be underestimated in the presence of an overall low burden of side effects.

Randomized prospective studies are required to assess the efficacy of monitoring, prophylaxis, and preemptive therapy to mitigate the risk of infections, hospital admission, and mortality in bendamustinetreated patients with NHL. These studies should consider characteristics of the patient, such as age and immune status, the type of NHL, the line of treatment, and the addition of other drugs, including rituximab.

Gabriele Magliano' ${ }^{1}$, Annarosa Cuccaro $^{3}$, Francesco d'Alo, ${ }^{1,2}$, Elena Maiolo ${ }^{2}$, Silvia Bellesi ${ }^{2}$, Stefan Hohaus ${ }^{1,2}$, Andrea Bacigalupo $^{1,2}$, Livio Pagano ${ }^{1,2}$.

${ }^{1}$ Sezione di Ematologia, Dipartimento di Scienze Radiologiche ed Ematologiche, Università Cattolica del Sacro Cuore, Roma

${ }^{2}$ Dipartimento di Diagnostica per Immagini, Radioterapia Oncologica ed Ematologia, Fondazione Policlinico Universitario A. Gemelli IRCCS, Roma;

${ }^{3}$ UOC Ematologia Aziendale, Azienda Toscana Nord-Ovest, Livorno, Italy.

Competing interests: The authors declare no conflict of Interest.

Correspondence to: Gabriele Magliano. Sezione di Ematologia, Dipartimento di Scienze Radiologiche ed Ematologiche, Università Cattolica del Sacro Cuore, Roma.

\section{References:}

1. Jares P, Campo E. Advances in the understanding of mantlecell lymphoma. Br J Haematol. 2008 Jun;142(2):149-65

2. Doorduijn JK, Kluin-Nelemans HC. Management of mantle cell lymphoma in the elderly patient. Clin IntervAging. 2013;8:1229-36

3. Flinn IW, van der Jagt R, Kahl BS, Wood P, Hawkins TE, Macdonald D, Hertzberg M, Kwan YL, Simpson D, Craig M, Kolibaba K, Issa S, Clementi R, Hallman DM, Munteanu M, Chen L, Burke JM. Randomized trial of bendamustine-rituximab or R-CHOP/R-CVP in first-line treatment of indolent NHL or MCL: the BRIGHT study. Blood. 2014 May 8;123(19):2944-52

4. Gafter-Gvili A, Ribakovsky E, Mizrahi N, Avigdor A, Aviv A, Vidal L, Ram R, Perry C, Avivi I, Kedmi M, Nagler A, Raanani P, Gurion R. Infections associated with bendamustine containing regimens in hematological patients: a retrospective multi-center study. Leuk 
Lymphoma. 2016;57(1):63-9

https://doi.org/10.3109/10428194.2015.1046862

5. Saito H, Maruyama D, Maeshima AM, Makita S, Kitahara H, Miyamoto K, Fukuhara S, Munakata W, Suzuki T, Kobayashi Y, Taniguchi H, Tobinai K. Prolonged lymphocytopenia after bendamustine therapy in patients with relapsed or refractory indolent B-cell and mantle cell lymphoma. Blood Cancer J. 2015 Oct 23;5(10):e362.

6. Martínez-Calle N, Hartley S, Ahearne M, Kasenda B, Beech A, Knight H, Balotis C, Kennedy B, Wagner S, Dyer MJS, Smith D, McMillan AK, Miall F, Bishton M, Fox CP. Kinetics of T-cell subset reconstitution following treatment with bendamustine and rituximab for low-grade lymphoproliferative disease: a population-based analysis. Br J Haematol. 2019 Mar;184(6):957-968

7. Fung M, Jacobsen E, Freedman A, Prestes D, Farmakiotis D, Gu X, Nguyen PL, Koo S. Increased Risk of Infectious Complications in Older Patients With Indolent Non-Hodgkin Lymphoma Exposed to Bendamustine. Clin Infect Dis. 2019 Jan 7;68(2):247-255

8. Hasegawa T, Aisa Y, Shimazaki K, Nakazato T. Cytomegalovirus reactivation with bendamustine in patients with low-grade B-cell lymphoma. Ann Hematol. 2015 Mar;94(3):515-7

9. Hosoda T, Yokoyama A, Yoneda M et al. bendamustine can severely impair T-cell immunity against cytomegalovirus. Leuk Lymphoma 2013; 54: 1327-1328. https://doi.org/10.3109/10428194.2012.739285

10. Pezzullo L, Giudice V, Serio B, Fontana R, Guariglia R, Martorelli MC, Ferrara I, Mettivier L, Bruno A, Bianco R, Vaccaro E, Pagliano P, Montuori N, Filippelli A, Selleri C. Real-world evidence of cytomegalovirus reactivation in non-Hodgkin lymphomas treated with bendamustine-containing regi-mens. Open Med (Wars). 2021 Apr 21;16(1):672-682.

11. Cona A, Tesoro D, Chiamenti M, Merlini E, Ferrari D, Marti A, Codecà C, Ancona G, Tincati C, d'Arminio Monforte A, Marchetti G. Disseminated cytomegalovirus disease after bendamustine: a case report and analysis of circulating B- and T-cell subsets. BMC Infect Dis. 2019 Oct 22;19(1):881

12. García Muñoz R, Izquierdo-Gil A, Muñoz A, Roldan-Galiacho V, Rabasa $\mathrm{P}$, Panizo C. Lymphocyte recovery is impaired in patients with chronic lymphocytic leukemia and indolent non-Hodgkin lymphomas treated with bendamustine plus rituximab. Ann Hematol. 2014 Nov;93(11):187987

13. Gafter-Gvili A, Ribakovsky E, Mizrahi N, Avigdor A, Aviv A, Vidal L, Ram R, Perry C, Avivi I, Kedmi M, Nagler A, Raanani P, Gurion R. Infections associated with bendamustine containing regimens in hematological patients: a retrospective multi-center study. Leuk Lymphoma. 2016;57(1):63-9 https://doi.org/10.3109/10428194.2015.1046862 